\title{
An Approach Towards the Integration of International Research Experiences for Underrepresented Students in Sweden, the Netherlands, and Austria
}

\author{
Dr. Claude Brathwaite, City College of New York, NYC Louis Stokes Alliance
}

Dr. Claude Brathwaite is currently the Project Administrator for the New York City Louis Stokes Alliance for Minority Participation in Science, Technology, Engineering and Mathematics (LSAMP). Claude initially attended Hostos Community College and later received his BS in Chemistry from the City College of the City University of New York and his Ph.D. in Organic Chemistry from the Graduate Center of the City University of New York. He was a Chancellor's Fellow (City University of New York) and a NIH Postdoctoral Fellow (Weill Cornell Medical College-Division of Molecular Medicine). As the Project Administrator of the LSAMP, he oversees the day-to-day operation of the NYC Louis Stokes Alliance program across the 18 member campuses of City University of New York. Claude also served as the Co-Director of the Black Studies Program at the City College and the Project Director of the City College Black Male Leadership and Mentoring Program. The Black Male Leadership and Mentoring Project (BMLMP) at the City College of New York, provides a support system during the critical stages of academic and career development.

\section{Dr. Julianne Vernon, University of Michigan}

Julianne Vernon is a Research Program Officer at the University of Michigan, the College of Literature, Science, and Arts where she is coordinating the implementation of faculty led research projects into introductory chemistry and biology lab courses. She received her bachelors of engineering in chemical engineering from the City College of New York and her doctorate degree at University of Florida in Environmental Engineering. She has experience developing international and national research experience for STEM majors. 


\title{
An Approach towards the Integration of International Research Experiences for Underrepresented Students in Sweden, the Netherlands, and Austria
}

\begin{abstract}
The New York City Louis Stokes Alliance for Minority Participation (NYC LSAMP) at the City University of New York (CUNY) has, since its inception in November 1992, been at the forefront of a concentrated effort to substantially increase the number of underrepresented minority students who pursue and graduate with Baccalaureate Degrees in Science, Technology, Engineering and Mathematics (STEM). Since its inception in November 1992, over 14,000 baccalaureate degrees have been awarded to underrepresented minority students at CUNY. The NYC LSAMP has been successful in establishing international collaborative partnerships in Sweden, the Netherlands, Brazil, Austria, Morocco and Colombia.
\end{abstract}

The multi-pronged approach consists of 1) collaborating with existing programs within the NSF and other federal agencies, 2) working collaboratively with a core of mentors/faculty who have international collaborations, 3) working closely with Departments, Institutes and Centers at CUNY who have international agreements, significant international research focus, and 4) working collaboratively with other Alliances, all of which have some developed program activities in international research.

By targeting participants of the LSAMP program in CUNY and nationally, the reported model will allow the United States to benefit from the local CUNY and national networks of over 350 colleges and universities that comprise the LSAMP program. At CUNY (and nationally), LSAMP programs are well poised to participate in international programs, and for Scholars to acquire training in an international collaborative environment, thereby contributing towards the development of a globally competent scientific and engineering workforce. From 2008 - 2016 over 170 NYC LSAMP Scholars have participated in International Research Experiences in 24 different countries.

This paper will emphasize the elements of the approach and integration into the LSAMP program operations with a focus on collaborations between NYC Alliance and three universities in Sweden (Royal Institute of Technology (KTH)), the Netherlands (Maastricht University) and Austria (TU- Graz and University of Graz). A total of fifty six (56) students participated from 2008 to 2016. Each collaborating site possessed unique training opportunities. At the Royal Institute of Technology the collaboration with an NSF funded IRE project, students were engaged in research primarily in the chemical engineering field. At Maastricht University, students were engaged in neuroscience anchored in one department with an on-site coordinator matriculated in a dual degree doctoral program at the CUNY Graduate Center and Maastricht University. A multi-disciplinary approach was applied in Austria with TU-Graz hosting the engineering students and the students in the life sciences were hosted by the University of Graz. 
Introduction

The Open Doors report published by the Institute of International Education, the leading not-forprofit educational and cultural exchange organization in the United States has shown that over the last decade, (2004/5 to 2014/15), a fifty-two percent (52\%) increase in the number of US studying abroad (broadly defined) and only a ten percent (10\%) increase in the number of minorities studying abroad in the same period. Similarly over the same period, STEM majors going abroad showed an increase of about eight percent (7.6\%). All minority students and STEM students accounted for $27 \%$ and $24 \%$ respectively, in $2014 / 2015^{1}$. The importance and benefits of STEM students having an international experience has been well documented ${ }^{2,3}$. Additionally, higher education is moving forward with embracing the concept of educating engineers as a global citizen ${ }^{4}$.

The NYC Alliance committed to integrating international activities officially launched in 2008 at the Annual Urban University Conference Series, with the theme of Explorations and Discovery. In 2014, the Annual Global CUNY Conference was inaugurated and is held during the International Studies Week serves as a Research Colloquium and Expo, focused on highlighting projects and programs underway across the university, which have an international focus, and allows for the active participation/inclusion of STEM students ${ }^{5}$. LSAMP Scholars in the last eight years participated in research experiences in England, Sweden, Poland, Scotland, Spain, Italy, Germany, Austria, France, the Netherlands, Japan, China, Singapore, Australia, Vietnam, Sri Lanka, Honduras, Colombia, Costa Rica, Ecuador, Mexico, Brazil, Jamaica, Dominican Republic, St. Kitts, Ethiopia, Togo, Ghana, South Africa and Morocco ${ }^{6}$.

In this paper we will summarize our approach to integrating an international research (IR) experience for minority students in STEM in Sweden, the Netherlands, and Austria from 2008 to present.

\section{NYC Alliance European Host Site Programs Overview}

Graz, Austria - The Marshall Plan scholarship, funded by the Austrian Marshall Plan Foundation. It is an academic exchange program established to finance scholarships and fellowships for academic exchange between Austria and the U.S., with a special focus on universities of applied sciences, such as University of Graz (Uni Graz) and technical universities like Technical University of Graz (TU Graz). The Marshall Plan Foundation offers up to 1,000 scholarships for American and Austrian students with funding of up to $€ 10,000$,- (at a minimum of $€ 3000$,6000) for at least three months.

Stockholm, Sweden - The CCNY-KTH exchange program has supported international summer research experiences for City College of New York (CCNY) students at the Royal Institute of Technology $(\mathrm{KTH})$ and KTH students at CCNY for the past eight years. The program has provided undergraduate and graduate CCNY/CUNY students with an international research experience in the collaborative research environment of several divisions at KTH. It has also provided summer research experiences for over $40 \mathrm{KTH}$ students at CCNY. The research activities at KTH have mainly been centered at three KTH schools; the School of Chemical 
Science and Engineering, the School of Biotechnology, and School of Industrial Engineering and Management.

Maastricht, Netherlands - At Maastricht University (MU), students are engaged in Neuroscience topics including the neural correlates of depression, Alzheimer's disease, Drug Abuse, Epigenetics. Students learn techniques such as Microscopy, Immunohistochemistry and Stereology. The School for Mental Health and Neuroscience (MHeNS) has its niche in the complex interplay between basic brain mechanisms, brain/neurocognitive function and psychopathology, with emphasis on prevalent psychiatric, neuropsychiatric and neurological conditions. The strength of MHeNS lies in the translational aspects of fundamental neuroscience towards applied neurodegenerative and neurological neuropsychiatric strategies.

Program Model

Study abroad courses that are faculty led and short term are seen as the major vehicles for students to integrate an international experience in their curriculum. The opposite is true for the NYC LSAMP model, which has a term length of 8 weeks or more typically in the summer. A summary of the program elements at each university site is shown in Table 1 . The eleven core elements of the program were deemed an integral component of the success. For example, the faculty led designation for the KTH program is linked to the career award of the faculty. TUGraz/Univ. Graz program is also faculty led, but is based in CUNY at the City College.

Exchange agreements with reciprocity also add strength to the relationship. We see the KTH and TU-Graz/Univ. Graz programs being quite similar in program elements. Both rely on a strong working relationship with the international/study abroad office at the two sites and depart from the National Science Foundation (NSF) model typically used for REU programs ${ }^{7}$. The MU program did not require this type of relationship. We utilized the role of an embedded site coordinator (LSAMP Doctoral candidate) to serve as a liaison to the MHeNS program researchers and administrative structures in the school.

Table 1: Program Elements at Research Site

\begin{tabular}{|c|c|c|c|}
\hline Program Elements & $\underset{⿱ ㇒}{ \pm}$ & $\stackrel{\gtrless}{\Sigma}$ & 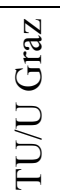 \\
\hline Site Coordinator & & $\mathrm{x}$ & \\
\hline CUNY Faculty Led & $\mathrm{x}$ & & $\mathrm{x}$ \\
\hline International Office & $\mathrm{x}$ & & $\mathrm{x}$ \\
\hline Reciprocal Program & $\mathrm{x}$ & & $\mathrm{x}$ \\
\hline Laboratory Bench Fee & & $\mathrm{x}$ & \\
\hline University Support & $\mathrm{x}$ & & \\
\hline Student Exchange Agreement & $\mathrm{x}$ & & $\mathrm{x}$ \\
\hline NSF Support & $\mathrm{x}$ & $\mathrm{x}$ & $\mathrm{x}$ \\
\hline Fellowship funding & & $\mathrm{x}$ & $\mathrm{x}$ \\
\hline Undergraduate participation & $\mathrm{x}$ & $\mathrm{x}$ & $\mathrm{x}$ \\
\hline Graduate participation & $\mathrm{x}$ & $\mathrm{x}$ & $\mathrm{x}$ \\
\hline
\end{tabular}


It should be noted that the three locations (Sweden, the Netherlands and Austria) are not in the top 20 destinations of US students studying abroad in 2014/2015 ${ }^{1}$. Additionally, the group is one hundred (100\%) minority (as defined by the NSF), and one hundred (100\%) STEM students, with the undergraduate and graduate participants being $53 \%$ and $47 \%$ respectively. In comparison to the reported US average of $87 \%$ graduate participants and $12 \%$ undergraduate participants and the standard NSF REU program supporting roughly $33 \%$ minority students ${ }^{1}$.

\section{Student Feedback}

An eight-question survey was designed and distributed online to the fifty-five (55) participants at the three European based sites. The three questions targeted 1) the reasons for participating in the IR program, 2) the goals of the students for participating and if the goals were met, and 3) the importance of the IR to career and academic goals. The survey had a response rate of $50 \%$ ( 28 participants).

Table 2, below, shows the response to Question 1, students' goals for participation in an international research program. Only $25 \%$ indicated that they participated to increase their ability to communicate in another language, compared to $78.6 \%$ indicated the goal was to enhance their resume and $82 \%$ to obtain a greater understanding of different cultures. The two leading goals of the survey participants were to conduct research in an international environment $(92.9 \%)$, and to increase their technical and scientific capabilities $(92.9 \%)$.

Table 2. Question 1of the IR Survey

\begin{tabular}{|l|c|}
\hline $\begin{array}{l}\text { Please select all that apply for your goals for the participation in the International } \\
\text { Research Program: }\end{array}$ & $\begin{array}{c}\text { Response } \\
\text { Percent }\end{array}$ \\
\hline To travel & $64.3 \%$ \\
\hline To experience new places & $71.4 \%$ \\
\hline To enhance resume & $78.6 \%$ \\
\hline To increase job or graduate school opportunities & $60.7 \%$ \\
\hline To increase my ability to communicate in a foreign language & $25.0 \%$ \\
\hline To obtain a greater understanding of different cultures & $82.1 \%$ \\
\hline To increase self-confidence & $50.0 \%$ \\
\hline To conduct research/work in an international environment & $92.9 \%$ \\
\hline To complete an international research project & $60.7 \%$ \\
\hline To increase my technical and scientific capabilities in my chosen career field & $92.9 \%$ \\
\hline
\end{tabular}

Table 3, below has the average results from, Question 2: Please rate how well the program goals were met in your opinion which was based on a five point Likert scale. The ability to communicate in a foreign language was rated the lowest average of 2.92 . The ability to speak a foreign language also rated low on the students' goal to participate in an IR program. The ability to enhance their resume, graduate school and job opportunities scored the highest (4.77) along with the ability to conduct research in an international environment was the second highest (4.68). Additionally, 1) $74 \%$ of survey participants rated the increase in technical and scientific capabilities, 2) $81 \%$ of survey participants rated increase in greater understanding of different 
cultures, and 3) 85\% rated the increase in self-confidence and conducting research in an international environment as a 4.0 (very well) or better.

Table 3. Question 2 of the IR Survey

\begin{tabular}{|l|c|}
\hline $\begin{array}{l}\text { Question 2: Please rate how well the program goals were met in your } \\
\text { opinion. Likert Scale (1:not well to 5: extremely well) }\end{array}$ & $\begin{array}{c}\text { Rating Average } \\
\text { (Standard Deviation) }\end{array}$ \\
\hline To travel and see new places & $4.65(0.56)$ \\
\hline To enhance resume, increase job, graduate school and job opportunities & $4.77(0.51)$ \\
\hline To increase my ability to communicate in a foreign language & $2.92(1.56)$ \\
\hline To obtain a greater understanding of different cultures & $4.31(0.84)$ \\
\hline To increase self-confidence & $4.37(0.74)$ \\
\hline To conduct research/work in an international environment & $4.68(0.75)$ \\
\hline To complete an international research project & $4.38(0.92)$ \\
\hline $\begin{array}{l}\text { To increase my technical and scientific capabilities in my chosen career } \\
\text { field }\end{array}$ & $4.28(0.98)$ \\
\hline
\end{tabular}

Table 4 below, shows the results from Question 3 of the IR survey. Overall, respondents demonstrated strong consistency in their responses to the areas measured. For the fourteen (14) areas explored, eight (8) of the areas were rated Agree or Strongly Agree by $90 \%$ to $100 \%$ of participants. Question item nos. 4, 12, 13, and 14 were among the highest by the respondents, while question item no. 5 (knowledge of a foreign language) rated the lowest. This is not surprising as, $89 \%$ of survey participants Agreed or Strongly Agreed that their understanding of diversity and their ability to work as a member of a team as increasing. Similarly, $96 \%$ of survey participants Agreed or Strongly Agreed that thinking critically, integrating scientific knowledge and the ability to communicate effectively across cultures were increased.

Table 4. Question 3 of the IR Survey

\begin{tabular}{|c|l|c|c|c|}
\hline $\begin{array}{c}\text { Question } \\
\text { Item No. }\end{array}$ & $\begin{array}{l}\text { Question 3: Please rate your level agreement to } \\
\text { the program increasing the following } \\
\text { statements. The program increased my: }\end{array}$ & $\begin{array}{c}\% \\
\% \\
\text { Participants } \\
\text { who Agree } \\
\text { Participants } \\
\text { who } \\
\text { Strongly } \\
\text { Agree } \\
\text { who Agree } \\
\text { or } \\
\text { Strongly } \\
\text { Agree }\end{array}$ \\
\hline 1 & knowledge of the host country/site & $36 \%$ & $57 \%$ & $93 \%$ \\
\hline 2 & knowledge of world geography and history & $43 \%$ & $39 \%$ & $82 \%$ \\
\hline 3 & $\begin{array}{l}\text { understanding of diversity and my ability to } \\
\text { work as a member of a team }\end{array}$ & $39 \%$ & $50 \%$ & $89 \%$ \\
\hline 5 & appreciation for multiple perspectives & $39 \%$ & $57 \%$ & $96 \%$ \\
\hline 7 & $\begin{array}{l}\text { knowledge of a foreign language } \\
\text { the country/host site }\end{array}$ & $50 \%$ & $14 \%$ & $64 \%$ \\
\hline
\end{tabular}




\begin{tabular}{|c|l|c|c|c|}
\hline 8 & awareness of ethnic and cultural differences & $43 \%$ & $50 \%$ & $93 \%$ \\
\hline 9 & awareness of my own identity and culture & $54 \%$ & $32 \%$ & $86 \%$ \\
\hline 10 & $\begin{array}{l}\text { opportunity to use my previous knowledge and } \\
\text { training in a new arena }\end{array}$ & $39 \%$ & $54 \%$ & $93 \%$ \\
\hline 11 & $\begin{array}{l}\text { scientific and technical abilities in the STEM } \\
\text { field }\end{array}$ & $36 \%$ & $54 \%$ & $89 \%$ \\
\hline 12 & $\begin{array}{l}\text { ability to think critically about a scientific or } \\
\text { technical challenge and integrate knowledge }\end{array}$ & $43 \%$ & $54 \%$ & $96 \%$ \\
\hline 13 & $\begin{array}{l}\text { ability to communicate effectively interact with } \\
\text { people from other cultures }\end{array}$ & $39 \%$ & $61 \%$ & $100 \%$ \\
\hline 14 & \begin{tabular}{l} 
ability to adapt unfamiliar settings and practices \\
\hline
\end{tabular} & $29 \%$ & $71 \%$ & $100 \%$ \\
\hline
\end{tabular}

Discussion and Conclusions

From 2011 to 2016, forty seven (47) students from Uni Graz and TU-Graz have participated in the two-week seminar course (reciprocal program for Austrian students). From 2011 to 2016, twenty (20) CUNY students have conducted research (8 to 12 weeks) at TU-Graz and Uni Graz. Of the twenty students (20) students, nine (9) were awarded the Marshall scholarship. This activity is seen as extremely important in providing leveraged support, as well as a valuable network of students in Graz for the participating students.

From 2008-2016 the participants at the three European sites, seven (13\%) have completed the doctoral degrees and twenty-five (45\%) are currently enrolled in doctoral programs and two in Medical Degree programs (Table 5 and 6). Two of the program participants completed their doctoral degree at one of the three international sites. Of students who participated while undergraduates $52 \%$ are now enrolled or have completed the doctoral degree.

Table 5: IR Participants Program Degree Outcomes

\begin{tabular}{|c|c|c|c|}
\hline $\begin{array}{c}\text { Scholar Academic } \\
\text { Attainment }\end{array}$ & $\stackrel{\underline{E}}{\underline{E}}$ & 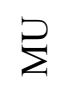 & $\overbrace{己}^{2}$ \\
\hline Total No. of Scholars & 25 & 16 & 14 \\
\hline $\mathrm{BA} / \mathrm{BS}$ & 2 & 1 & 1 \\
\hline MS/MA & 5 & 3 & 1 \\
\hline Ph.D. completion & 3 & 2 & 2 \\
\hline Ph.D. (International) & (1) & 1 & - \\
\hline MD & 1 & 1 & - \\
\hline Current Doctoral & 12 & 6 & 7 \\
\hline Current MA/MS & 1 & & 1 \\
\hline Unknown & 1 & 2 & 2 \\
\hline
\end{tabular}

Table 6: Institutions of Current Doctoral Candidates

\begin{tabular}{|l|c|}
\hline Doctoral Institution & $\begin{array}{c}\text { Number of Participants } \\
\text { Attending }\end{array}$ \\
\hline
\end{tabular}




\begin{tabular}{|l|l|}
\hline CUNY Graduate Center & 6 \\
\hline SUNY Stony Brook, Buffalo, Downstate & 3 \\
\hline Rutgers University & 2 \\
\hline University of Michigan & 1 \\
\hline Weil Cornell & 1 \\
\hline UC Los Angeles, Santa Barbara, Irvine & 3 \\
\hline Stanford & 1 \\
\hline University of Rochester & 1 \\
\hline University of South Florida & 1 \\
\hline Rensselaer Polytechnic & 1 \\
\hline UMass Amherst & 1 \\
\hline Pennsylvania State University & 2 \\
\hline Indiana University & 1 \\
\hline New Jersey Institute of Technology & 1 \\
\hline
\end{tabular}

The NYC LSAMP program with a close working collaborative relationship across five universities, (City University of New York, Royal Institute of Technology, Maastricht University, University of Graz and Technical University of Graz), has been able to leverage financial resources, existing programming, and an international research network to successfully integrate the high impact activity of International Research into the NYC LSAMP program operation. Examined outcomes are in-keeping with a recent study ${ }^{8}$. Participants report high levels of satisfaction with the program, viewing the activity as an important component of their professional, educational and academic experience and advancement in the workforce and in graduate school. We hope to increase survey response rates by making it a required task for the end of the program completion. LSAMP participants value the opportunity to work in an international environment, increasing their technical and scientific capabilities while integrating scientific knowledge and increasing the ability to communicate effectively across cultures. The ability to adapt to unfamiliar settings and practices was also seen by participants as a valued outcome of the experience, and is extremely important to academic and professional advancement. This is borne out by the high graduate school attendance rate of participants and the progression to doctoral study $(58 \%)$.

\section{Acknowledgements}

We acknowledge the support of the faculty and staff of CUNY in supporting the NYC Alliance activities, and the four participating universities in Austria (Technical University of Graz and the University of Graz), the Netherlands (Maastricht University) and Sweden (Royal Institute of Technology). We thank the International Offices at KTH, Uni Graz and TU-Graz for their support of our students during their stay and Dr. Harry Steinbusch of Masstricht University, and Dr. Ilona Kretzschmar of the City College for support and guidance of the programming. We acknowledge the funding support of the NSF to the CUNY NYC Alliance, and the IRES program, and the Marshall Scholarship Program for funding this collaborative endeavor.

\section{References}


1. Institute of International Education. "Fields of Study of U.S. Study Abroad Students, 2000/01-2014/15." Open Doors Report on International Educational Exchange, (2016).

2. Institute of International Education. "Fields of Study of U.S. Study Abroad Students, 2000/01-2010/11." Open Doors Report on International Educational Exchange, (2012).

3. National Academy of Engineering. "The Engineer of 2020: Visions of Engineering in the New Century", 35 (2004).

4. Grandin, John M., and E. Dan Hirleman. "Educating engineers as global citizens: A call for action/A report of the national summit meeting on the globalization of engineering education." Online Journal for Global Engineering Education 4.1 (2009): 1.

5. New York City Louis Stokes Alliance Impact Report 1992-2015 (2012 and 2015).

6. Vernon, Julieanne., and Brathwaite, Claude., "Authentic International Research Experience: Program Model in Cartagena, Colombia" in the Proceedings of the 2016 ASEE Annual Conference, Paper ID \# 15025, New Orleans, June, 2016.

7. National Science Foundation REU Sites-Looking Beyond the Borders, http://www.nsf.gov/pubs/2006/nsf06204/index.html.

8. Brey, Eric M., Campanile, Megan F., and Lederman, Norman G., "Evaluation of a Nine Year Summer Undergraduate Research Program in Biomedical Engineering" in the Proceedings of the 2015 ASEE Annual Conference, Paper ID \#12298, Seattle, WA, June, 2015. 